\title{
PREVALENCE OF ENTEROCOCCAL INFECTIONS AND THEIR ANTIBIOTIC SUSCEPTIBILITY PATTERN WITH SPECIAL REFERENCE TO HLAR IN SOUTH EAST RAJASTHAN
}

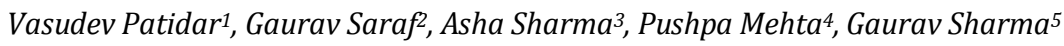

${ }^{1}$ PhD. Scholar, Department of Microbiology, Suresh Gyan Vihar University, Jagatpura, Jaipur, Rajasthan.

${ }^{2}$ Post Graduate Student, Department of Microbiology, Jhalawar Medical College, Jhalawar, Rajasthan.

${ }^{3}$ Associate Professor, Department of Zoology, P.G. College Dausa, Rajasthan.

${ }^{4}$ Professor and HOD, Department of Microbiology, Jhalawar Medical College, Jhalawar, Rajasthan.

5 Professor and HOD, Department of Applied \& Biosciences, Suresh Gyan Vihar University, Jagatpura, Jaipur, Rajasthan.

\begin{abstract}
\section{BACKGROUND}

Enterococci are Gram positive bacteria, which mainly form gastrointestinal flora. Enterococcus has consistently ranked among the most frequent pathogen causing significant hospital-acquired infections. They were classified as group D streptococci. Clinically, the most important species associated with human infections are E. faecalis and E. faecium. Enterococcus develops acquired resistance to several classes of antibiotics either by mutation or by transfer of plasmids and transposons. The acquisition of highlevel aminoglycoside resistance and vancomycin resistance limits the therapeutic options available for clinicians. The present study was undertaken to determine the antimicrobial susceptibility pattern of the Enterococcus spp. with special reference to High Level Aminoglycoside Resistance (HLAR).
\end{abstract}

\section{MATERIAL AND METHODS}

The present study was done at tertiary care health centre in South East Rajasthan. A total of 100 isolates taken from both OPD and IPD patients for a period of one year are included in the study.

\section{RESULTS}

A total 100 isolates of Enterococcus from various clinical samples were taken for the current study. In the current study seven species were identified which are E. faecalis, E. faecium, E. raffinosus, E. durans, E. mundtii, E. gallinarum, and E. solitarius. Among all the species, E. faecalis (57) was the predominant isolate in all the samples followed by E. faecium (33), E. raffinosus (4), E. durans and E. mundtii ( 2 each), E. gallinarum and E. solitarius (1 each).

\section{CONCLUSION}

Enterococcal infections are difficult to treat, as this bacterium has intrinsic resistance to various antibiotics and also can acquire resistance against other antibiotics available for treatment. In the case of complicated Enterococcus infection combination of cephalosporin and aminoglycoside are usually used, but in High Level Aminoglycoside Resistance (HLAR) even this combination is unable to inhibit the organism. So it is important to test Enterococci for HLAR. The present study concluded that there is an emergence of HLAR in our setup and as these isolates have very limited treatment options, so the use of higher antibiotics and combination therapy must be started only on the grounds of sensitivity pattern.

\section{KEYWORDS}

Enterococcus, HLAR (High Level Aminoglycoside Resistance), Drug Resistance, Hospital Acquired Infection.

HOW TO CITE THIS ARTICLE: Patidar V, Saraf G, Sharma A, et al. Prevalence of enterococcal infections and their antibiotic susceptibility pattern with special reference to HLAR in south east Rajasthan. J. Evolution Med. Dent. Sci. 2016;5(35):1973-1975, DOI: $10.14260 /$ jemds/2016/466

\section{INTRODUCTION \\ Enterococci are Gram positive bacteria, naturally occurring in the soil, water, plants and in animals. In humans, it mainly forms the gastrointestinal flora. It plays a dual role in human ecology as a commensal and as an opportunistic pathogen. Enterococcus has consistently ranked among the most frequent pathogens causing significant hospital-acquired infections.1,2 They can lead to a variety of clinical conditions including endocarditis, bacteraemia, meningitis, wound and urinary tract infections.}

Financial or Other, Competing Interest: None.

Submission 13-03-2016, Peer Review 09-04-2016,

Acceptance 14-04-2016, Published 29-04-2016.

Corresponding Author:

Dr. Pushpa Mehta,

C/o Vasudev Patidar,

Near Gayatri Mandir, NH-12,

Jhalawar-326001, Rajasthan.

E-mail: vasudevpatidar235@gmail.com

DOI: 10.14260/jemds/2016/466
Several studies have revealed the involvement of Enterococci in infections associated with indwelling devices like catheter-associated infections and implant infections. ${ }^{1,2,3}$

Enterococcus is classified as group D streptococci. The most important species associated with human infections are E. faecalis and E. faecium. ${ }^{3,4}$ Of them E. faecalis is the most common pathogenic species, but E. faecium is of growing importance, as it is more frequently resistant to antimicrobials. ${ }^{4}$ Enterococcus can develop acquired resistance to several classes of antibiotics either by mutation or by receipt of foreign genetic material through the transfer of plasmids and transposons. The acquisition of High-Level Aminoglycoside Resistance (HLAR) and vancomycin resistance limits the therapeutic options available for treatment. 4,5

The present study was undertaken with the objective to study the isolation, speciation and characterization of Enterococci from various clinical samples and to determine 
the antimicrobial susceptibility pattern of Enterococcus spp. with special reference to HLAR.

\section{MATERIAL AND METHODS}

The present study was done at tertiary health care centre in south east part of Rajasthan. A total of 100 isolates were taken from both OPD and IPD patients for a period of one year. Enterococcus isolates identified up to species level by using commercial biochemical identification panel, KB005A HiStrep $^{\mathrm{TM}}$ Identification Kit (Hi-Media). The panel contains 12 biochemical reactions, i.e. Voges Proskauer, Esculin hydrolysis, PYR test, ONPG, Arginine dihydrolase test, Glucose, Lactose, Arabinose, Sucrose, Sorbitol, Mannose and Raffinose fermentation. Antibiotic susceptibility and High Level Aminoglycoside resistance (HLAR) was studied using gentamicin $(120 \mu \mathrm{g})$ disc by Bauer-Kirby test. ${ }^{2}$ The antibiotics which were tested for susceptibility are Ampicillin/Sulbactam, Piperacillin/Tazobactam, Ofloxacin, Norfloxacin, Amikacin, Netilmicin, Nitrofurantoin (urinary isolates only) and high level Gentamicin disc $(120 \mu \mathrm{g})$. The antibiotic discs were also procured from Hi-Media.

\section{RESULTS}

A total 100 isolates of Enterococci from both outdoor and indoor patients, isolated during one year (January 2015 to December 2015) from various clinical samples were taken for the current study. All the isolates were identified up to species level by commercial biochemical identification panel, KB005A HiStrep ${ }^{\mathrm{TM}}$ Identification Kit (Hi-Media) Fig. 1. In the current study seven different species were identified which are E. faecalis, E. faecium, E. raffinosus, E. durans, E. mundtii, E. gallinarum and E. solitarus. Among all the species, E. faecalis (57) was the predominant isolate in all the clinical samples followed by E. faecium (33), then E. raffinosus (4), E. durans and E. mundtii ( 2 each), E. gallinarum and E. solitarus (1 each) [Table 1].
Maximum isolates of Enterococcus were in pus (44) followed by urine (32), blood (12), throat swab (6) and vaginal swab (6) Table 1. E. faecalis show remarkable resistance to beta-lactam group Ampicillin/sulbactam 32 (56.14\%) and Piperacillin/Tazobactam 31 (54.3\%) in Fluoroquinolones group E. faecalis showed more resistance to Norfloxacin 37 (64.9\%) than Ofloxacin 27 (47.3\%). Gentamicin (120 $\mu \mathrm{g})$ was used to test for high level Aminoglycosides resistance and we found a low incidence of HLAR in our setup, i.e. 09 (15\%). Among urinary isolates, 6 out of 18 isolates showed resistance to Nitrofurantoin (33\%).

E. faecium showed comparatively less resistance to betalactam group Ampicillin/sulbactam 13 (39.39\%) and Piperacillin/Tazobactam 5 (15.15\%). E. faecium showed more resistance against Fluoroquinolone group - Norfloxacin 23 (69.69\%), Ofloxacin 15 (45.45\%). HLAR among E. faecium was 11 (33.33\%), which is higher than E. faecalis. Urinary isolates of E. faecium also showed more resistance, 4 out of 10 (40\%) to Nitrofurantoin in comparison to E. faecalis. Rest of the species were isolated in very less numbers and they showed sensitivity to almost all antibiotics Table 2 .

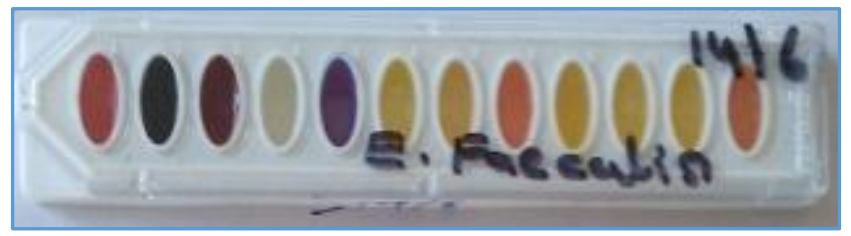

Fig. 1

Fig. 1: Commercial biochemical identification panel, KB005A HiStrep ${ }^{\mathrm{TM}}$ Identification Kit (Hi-Media) Wells from left to right Voges Proskauer, Esculin hydrolysis, PYR test, ONPG, Arginine dihydrolase test, Glucose, lactose, arabinose, sucrose, sorbitol, Mannose and Raffinose fermentation. Depicting reaction of E. faecalis.

\begin{tabular}{|c|c|c|c|c|c|}
\hline Enterococcus Spp. & Pus (\%) & Urine (\%) & Blood (\%) & Throat Swab (\%) & Vaginal Swab (\%) \\
\hline E. faecalis (N=57) & $25(43.8)$ & $18(31.5)$ & $7(12.2)$ & $4(07.0)$ & $3(05.2)$ \\
\hline E. faecium (N=33) & $16(48.4)$ & $10(30.3)$ & $3(9.09)$ & $2(06.1)$ & $2(06.06)$ \\
\hline E. raffinosus (N=4) & $2(50.0)$ & $1(25.0)$ & 0 & 0 & $1(25.0)$ \\
\hline E. durans (N=2) & 0 & $1(50.0)$ & $1(50.0)$ & 0 & 0 \\
\hline E. mundtii (N=2) & 0 & $1(50.0)$ & $1(50.0)$ & 0 & 0 \\
\hline E. gallinarum (N=1) & $1(100)$ & 0 & 0 & 0 & 0 \\
\hline E. solitarius (N=1) & 0 & $1(100)$ & 0 & 0 & $\mathbf{6}$ \\
\hline Total & $\mathbf{4 4}$ & $\mathbf{3 2}$ & $\mathbf{1 2}$ & $\mathbf{6}$ & \\
\hline \multicolumn{7}{r}{} \\
\hline
\end{tabular}

\begin{tabular}{|c|c|c|c|c|c|c|c|c|}
\hline & AS & AMK & OF & NX & NIT & NET & PIT & HLG \\
\hline \multirow[t]{2}{*}{ E. faecalis } & S-25 & S-41 & S-30 & $\mathrm{S}-20$ & $\mathrm{~S}-12$ & S-41 & S-26 & S-48 \\
\hline & $\mathrm{R}-32$ & $\mathrm{R}-16$ & $\mathrm{R}-27$ & $\mathrm{R}-37$ & R-06 & $\mathrm{R}-16$ & $\mathrm{R}-31$ & R-09 \\
\hline \multirow[t]{2}{*}{ E. faecium } & S-20 & S-20 & $\mathrm{S}-18$ & S-10 & S-6 & S-19 & S-28 & S-22 \\
\hline & $\mathrm{R}-13$ & $\mathrm{R}-13$ & $\mathrm{R}-15$ & $\mathrm{R}-23$ & $\mathrm{R}-4$ & $\mathrm{R}-14$ & $\mathrm{R}-5$ & $\mathrm{R}-11$ \\
\hline \multirow[t]{2}{*}{ E. raffinosus } & S-4 & S-4 & S-4 & S-0 & S-0 & S-1 & S-1 & S-1 \\
\hline & $\mathrm{R}-0$ & $\mathrm{R}-0$ & $\mathrm{R}-1$ & $\mathrm{R}-1$ & $\mathrm{R}-1$ & $\mathrm{R}-0$ & $\mathrm{R}-0$ & $\mathrm{R}-0$ \\
\hline \multirow[t]{2}{*}{ E. durans } & $S-1$ & S-2 & S-2 & S-2 & S-1 & S-2 & S-1 & S-2 \\
\hline & $\mathrm{R}-1$ & $\mathrm{R}-0$ & $\mathrm{R}-0$ & $\mathrm{R}-0$ & $\mathrm{R}-0$ & $\mathrm{R}-0$ & $\mathrm{R}-1$ & $\mathrm{R}-0$ \\
\hline \multirow[t]{2}{*}{ E. mundtii } & S-2 & S-2 & S-2 & S-2 & S-1 & S-2 & S-2 & S-2 \\
\hline & $\mathrm{R}-0$ & R-0 & $\mathrm{R}-0$ & $\mathrm{R}-0$ & $\mathrm{R}-0$ & R-0 & R-0 & $\mathrm{R}-0$ \\
\hline \multirow[t]{2}{*}{ E. gallinarum } & S-1 & $\mathrm{S}-1$ & S-1 & S-1 & $\mathrm{S}-0$ & S-1 & $\mathrm{S}-0$ & S-1 \\
\hline & $\mathrm{R}-0$ & $\mathrm{R}-0$ & $\mathrm{R}-0$ & $\mathrm{R}-0$ & $\mathrm{R}-0$ & R-0 & R1 & $\mathrm{R}-0$ \\
\hline \multirow[t]{2}{*}{ E. solitarius } & S-1 & S-1 & S-1 & S-1 & S-0 & S-1 & $S-1$ & S-1 \\
\hline & R-0 & $\mathrm{R}-0$ & R-0 & $\mathrm{R}-0$ & R-1 & R-0 & R-0 & R-0 \\
\hline
\end{tabular}


AS=Ampicillin/sulbactam,$\quad$ AMK=Amikacin, $\quad$ OF=Ofloxacin,$\quad$ NX=Norfloxacin, $\quad$ NIT=Nitrofurantoin, NET=Netilmicin, PIT=Piperacillin/Tazobactam, HLG=High level gentamicin, $S=$ Sensitive, R=Resistance.

\section{DISCUSSION}

Enterococcal infections are difficult to treat, as these bacteria have intrinsic resistance to various antibiotics and in addition to this they can acquire resistance to all the antibiotics available for treatment.1,2,4,5 In the case of complicated Enterococcal infection a combination of Cephalosporin and Aminoglycoside is usually used, although it shows intrinsic resistance against them if given single, but shows synergism when given in combination. ${ }^{2}$ In case of high level aminoglycoside resistance, even this combination is unable to inhibit the organism. So it is important to test Enterococci for HLAR prior to start of combination therapy. High levels aminoglycoside resistant Enterococci were first reported in France in 1979 and since then have been isolated from all the continents. ${ }^{6}$ The only option for treatment for HLAR is glycopeptides, i.e. Vancomycin or Teicoplanin.

In the present study, the predominant isolate was E. faecalis (57). Most of the Enterococci were isolated from pus (44) followed by urine (32), blood (12), throat swab and vaginal swab (6). There is higher incidence of Enterococcal infections was found in females (52) than in males (48). The most affected age group with Enterococcal infections was 2130 years (27), which shows that Enterococcal infection is more common in young population [Table 3]. In the present study, Enterococcal infections was more common in OPD (52) than in IPD cases (48). UTI due to Enterococci is almost equal in both OPD (17) and IPD (15) cases. Blood culture of Enterococci was predominant in IPD (10), as most of the samples of blood culture were asked in IPD patients [Table 4]. The total isolates of Enterococci, which showed HLAR is $20(09+11)$ which is concordant to study of Purva Mathur et al (26\%).

Although, the rate of HLAR in a particular setup depends on the antibiotic usage in an institution, that is the reason why in various studies the percentage of HLAR ranges from $7 \%$ to almost 100\%.5,6,7 High level aminoglycoside resistant Enterococci often have plasmids, which carry determinants encoding resistance to other antibiotics. It is notable that Woodford et al demonstrated linkage of the vancomycin resistance and high-level gentamicin resistance genes on the same plasmid in a clinical isolate of E. faecalis and the presence of the gentamicin resistance gene on a variety of physically distinct conjugative and non-conjugative plasmids in $\mathrm{E}$. faecalis facilitates the wide dissemination of multidrugresistant strains with characteristics that allow them not only to persist but also to spread.7,8,9,10

\begin{tabular}{|c|c|c|c|}
\hline Age & Male & Female & Total \\
\hline 0 - 1 year & 4 & 3 & 7 \\
\hline 1 - 10 year & 3 & 4 & 7 \\
\hline 11 - 20 year & 7 & 7 & 14 \\
\hline 21 - 30 year & 11 & 16 & 27 \\
\hline 31 - 40 year & 9 & 6 & 15 \\
\hline 41 - 50 year & 5 & 9 & 14 \\
\hline 51 - 60 year & 6 & 3 & 9 \\
\hline 61 - 70 & 3 & 4 & 7 \\
\hline T0TAL & 48 & 52 & 100 \\
\hline Table 3: Distribution of Enterococcal Infection in \\
Various Age Groups and Sex \\
\hline \multicolumn{4}{|c|}{}
\end{tabular}

\begin{tabular}{|c|c|c|c|c|c|c|}
\hline & Pus & Urine & Blood & Throat & $\begin{array}{c}\text { Vaginal } \\
\text { Swab }\end{array}$ & Total \\
\hline OPD & 25 & 17 & 2 & 4 & 4 & 52 \\
\hline IPD & 19 & 15 & 10 & 2 & 2 & 48 \\
\hline Total & $\mathbf{4 4}$ & $\mathbf{3 2}$ & $\mathbf{1 2}$ & $\mathbf{6}$ & $\mathbf{6}$ & $\mathbf{1 0 0}$ \\
\hline \multicolumn{7}{|c|}{ Table 4: Distribution of Cases in OPD and IPD } \\
\hline
\end{tabular}

\section{CONCLUSION}

The present study concluded that there is an emergence of HLAR in our setup and as these isolates have very limited treatment options combination therapy must be started based only on sensitivity pattern with lesser use of higher antibiotics like vancomycin and teicoplanin, so that resistant strains to these antibiotics can be prevented from emerging. It is encouraging that we have less percentage of HLAR in E. faecalis (15\%), which is the principal isolate in our study, but it is more in E. faecium (33\%). So there is a chance of increase in HLAR in other species also by transfer of resistant plasmids among them.

\section{REFERENCES}

1. Randhawa VS, Kapoor L, Singh V, et al. Aminoglycoside resistance in enterococci isolated from paediatric septicaemia in a tertiary care hospital in north India. Indian J Med Res 2004;19(Suppl):77-9.

2. Koneman EW, Washington C Winn. Color atlas and text book of diagnostic microbiology. Philadelphia, Lippincott Williams and Wilkins 2006; $6^{\text {th }}$ edn.

3. Purva Mathur, Arti Kapil, Rachna Chandra, et al. Antimicrobial resistance in enterococcus faecalis at a tertiary care centre of northern India. Indian J Med Res 2003;118:25-8.

4. Agarwal VA, Jain YI, Pathak AA. Concomitant high level resistance to penicillin and aminoglycosides in enterococci at Nagpur, central India. Indian J Med Microbiol 1999;17:85-7.

5. Blandine Mulin, Pascale Bailly, Michelle Thouverex, et al. Clinical and molecular epidemiology of hospital enterococcus faecalis isolates in eastern France. Clin Microbiol Infect 1999;5(3):149-57.

6. Karmarkar MG, Edwin S, Gershom, et al. Enterococcal infections with special reference to phenotypic characterization \& drug resistance. Indian J Med Res 2004;119(Suppl):22-5.

7. Woodford N, Jones BL, Baccus Z, et al. Linkage of vancomycin and high-level gentamicin resistance genes on the same plasmid in a clinical isolate of enterococcus faeculis. J Antimicrobial Chemotherapy 1995;35:179-84.

8. Guido Werner. Current trends of emergence and spread of vancomycin-resistant enterococci. http:// www.ecdc. europa.eu/en/publications/Publications/1011 SUR Annual Epidemiological Report on Communicable Diseases in Europe pp303-54.

9. Liu Y, Liu K, Lai J, et al. Prevalence and antimicrobial resistance of enterococcus species of food animal origin from beijing and shandong province, China. Journal of Applied Microbiology 2013;114(2):555-63.

10. Richards MJ, Edwards JR, Culver DH, et al. Nosocomial infections in combined medical-surgical intensive care units in the united states. Infect Control Hosp Epidemiol 2000;21(8):510-5. 